\title{
TOXICITY OF FIELD-AGED PERMETHRIN-LOADED ATTRACTICIDES ON Choristoneura rosaceana (HARRIS) AND Pandemis pyrusana KEARFOTT (LEPIDOPTERA: TORTRICIDAE) ADULT MALES AND FEMALES
}

\author{
Tomislav Curkovic ${ }^{*}$, Jay F. Brunner ${ }^{2}$, and John J. Brown ${ }^{3}$
}

\begin{abstract}
Lethal and sub lethal effects were evaluated in the laboratory on Choristoneura rosaceana (Harris) and Pandemis pyrusana Kearfott males exposed to an attracticide loaded with permethrin and aged in the field. The effect of pairing conspecific females with previously intoxicated males was also evaluated. In both species a significantly greater mortality of male moths $(\geq 95 \%)$ was observed $24 \mathrm{~h}$ after exposure to the attracticide formulation. Likewise, high levels of knock down $(\geq 75 \%)$ were observed in males of both species $1 \mathrm{~h}$ after attracticide exposure. In females, knock down was $\geq 2.5 \%$ and mortality $\geq 3.3 \%$ after pairing with intoxicated males. Leg autotomy in males was at least $73 \%$ in C. rosaceana and $\geq 41 \%$ in P. pyrusana, $24 \mathrm{~h}$ after attracticide exposure; whereas it was only $\geq 10 \%$ among females of both species after pairing with intoxicated males. Moths exposed to an attracticide blank (permethrin-free) showed significantly lower effects in all parameters (0-3.3\%). Fecundity and fertility were also significantly affected after pairing females with intoxicated males. There was no significant decrease in mortality, leg autotomy, and fecundity associated with age of the attracticide. Results suggest a high potential for the use of attracticides against these two tortricid species.
\end{abstract}

Key words: bioassay, fecundity, fertility, knockdown, leg autotomy, lethal effects, mortality, sub lethal effects.

\section{INTRODUCTION}

Several leafroller species are present in Washington, USA, but two, Choristoneura rosaceana (Harris) (Obliquebanded leafroller) and Pandemis pyrusana Kearfott (Pandemis leafroller) are the most important in commercial orchards (Beers et al., 1993). Until the 1990s, leafrollers were adequately controlled by pre-bloom organophosphate insecticide applications and summer treatments applied against codling moth, Cydia pomonella (L.). However, elimination or restrictions placed on this insecticide class due to the implementation of the Food Quality Protection Act of 1996, adoption of pheromone

\footnotetext{
${ }^{1}$ Universidad de Chile, Facultad de Ciencias Agronómicas, Casilla 1004, Santiago, Chile." Corresponding author (tcurkovi@uchile.cl). ${ }^{2}$ Washington State University, Tree Fruit Research and Extension Center, 1100 N. Western Ave., Wenatchee, 98801, Washington, USA. (jfb@wsu.edu).

${ }^{3}$ Washington State University, Dept. of Entomology, Pullman, 99163, Washington, USA. (brownjj@wsu.edu).

Received: 07 December 2007.

Accepted: 19 August 2008.
}

mating disruption for codling moth (Brunner, 1999), and detection of resistance to some newly registered insecticides (Dunley et al., 2006) have raised the pest status of leafrollers in apple (Malus domestica Borkh.) production making them second in importance only to the codling moth.

Attracticides containing killing agents have been reported for several tree fruit pest tortricids, e.g. Epiphyas postvittana (Walker) (Suckling and Brockerhoff, 1999), Cydia pomonella (L.) (Charmillot et al., 2000; Curkovic and Brunner, 2003), Cydia molesta (Busck) (Evenden and McLaughlin, 2005), and C. rosaceana and P. pyrusana (Curkovic and Brunner, 2007). This pest control technique relies on point source applications (Krupke et al., 2002), and its efficacy depends on males contacting the source (Curkovic and Brunner, 2005).

Data about mortality, residual, or sub-lethal effects from insecticides on adult moths are scarce (Phelan and Baker, 1987; Moore and Tabashnik, 1989; Curkovic and Brunner, 2005) but necessary to develop attracticides (Curkovic, 2004). Sub-lethal effects have been reported for some adult moths exposed to insecticides using different bioassays (Haynes et al., 1986; Tabashnik et al., 
1988; Schumacher et al., 1997; Curkovic and Brunner, 2005). The objective of this study was to evaluate lethal and sub-lethal effects of an attracticide -aged under field conditions- on C. rosaceana and P. pyrusana males and on female moths caged with intoxicated conspecific males.

\section{MATERIALS AND METHODS}

C. rosaceana and P. pyrusana were obtained from colonies reared on an artificial pinto-bean (Phaseolus vulgaris L.) diet following the Shorey and Hale methods (1965). Colonies were maintained under constant conditions $\left(23 \pm 1{ }^{\circ} \mathrm{C}\right.$, photoperiod 16:8) at the Washington State University Tree Fruit Research and Extension Center, Wenatchee, Washington, USA. The $P$. pyrusana colony was started from larvae collected in a commercial apple orchard near Yakima, Washington, in 1985, and the C. rosaceana colony from larvae collected in a commercial orchard near Mattawa, Washington, in 1990. The populations would have been exposed to organophosphate insecticides prior to collection, though not to pyrethroid insecticides. The constant laboratory rearing without a subsequent introduction of wild individuals has resulted in colonies of both species highly susceptible to most insecticides (Dunley et al., 2006).

Pupae were washed in a 5\% bleach solution, separated by sex, placed in small groups in plastic cups $(96 \mathrm{~mL}$ closed plastic cups, P325, Solo Cup Co., Urbana, Illinois, USA), provided with $30 \%$ honey-water solution, and kept under constant conditions (as described above). Male and female pupae were held in separate chambers. Upon emergence adults were placed individually in 96 $\mathrm{mL}$ plastic cups and provided with a $30 \%$ honey-water solution via cotton wicks, awaiting bioassays to be conducted. In the experiments, 2 to 4-days old males and females were used, since $>98 \%$ of individuals have been shown to survive in these conditions (Curkovic, 2004) and to be sexually mature at that age (Delisle, 1995).

The attracticide base was prepared using a matrix (grease, Last Call $^{\mathrm{TM}}$, IPM Technologies, Portland, Oregon, USA) containing an ultraviolet stabilizer $(\sim 70 \%)$, a thickener and a sticker $(\sim 30 \%)$. The procedure has been described in Curkovic (2004). The attracticide matrix was mixed with pheromone (Bedoukian Research Inc., Danbury, Connecticut, USA, purity being in all cases higher than 95\%) and permethrin (technical, 92\% purity), referred to as the attracticide treatment, or prepared without adding permethrin, referred to as the attracticide blank. Fifty grams of the grease matrix in a vial $(100 \mathrm{~mL})$ were constantly mechanically stirred while in a warm $\left(45 \pm 5^{\circ} \mathrm{C}\right)$ water bath, while permethrin and pheromone components (reported blends for each species, i.e. Roelofs et al., 1977; Vakenti et al., 1988) were added to obtain concentrations of $6 \%$ and $1.6 \%$, respectively. This mixture was then placed in $10 \mathrm{~mL}$ syringes and stored in a cold room $\left(0 \pm 1^{\circ} \mathrm{C}\right)$. Each syringe was brought to room temperature $\left(23 \pm 1{ }^{\circ} \mathrm{C}\right)$ for $15-30$ min prior to its use in experiments.

Twenty attracticide droplets $(\sim 50 \mu \mathrm{L}$ each) were applied on aluminum foil covering pieces of plastic sheet (strips, $40 \mathrm{~cm}$ length). Each strip was protected from contamination by a mesh screen cover and hung from apple tree branches in an unsprayed orchard at the Washington State University Tree Fruit Research and Extension Center. Several strips of the attracticide treatment and the attracticide blank were prepared and aged. Two of the strips were collected on day 0 (not aged) and every 10 days thereafter over a 30 days period. The aged samples were stored at $-14{ }^{\circ} \mathrm{C}$ until used for bioassays. Environmental measurements of daily maximum and minimum temperature, wind speed and direction and precipitation were recorded at a Washington State University Public Agriculture Weather System installation located less than $400 \mathrm{~m}$ away from the site where the attracticide was aged. Environmental parameters were averaged over the study period.

Male moths were held using a modified vacuum device as previously described by Curkovic and Brunner (2005). A moth was held by a vacuum and brought close to an attracticide droplet randomly selected from each field age class and allowed a brief contact, i.e. approximately $1 \mathrm{~s}$ with one or more legs. Nansen and Phillips (2004) have reported a similar bioassay. After contact with the attracticide the moth was placed in a plastic cup $(96 \mathrm{~mL})$, kept under constant conditions $\left(23 \pm 1{ }^{\circ} \mathrm{C}\right.$, photoperiod 16:8) and supplied with a honey-water solution. Each strip was used only twice to avoid contamination by moth scales.

The effect of an intoxicated male on a non-intoxicated female was assessed by pairing a virgin (and not exposed to attracticides) female in a clean $96 \mathrm{~mL}$ plastic cup with a male added $5 \mathrm{~s}$ after he had been exposed (as described above) to an attracticide treatment, attracticide blank or vacuum handled. A cotton wick with $30 \%$ honey water solution was provided for each couple and the cups were kept under constant conditions $\left(23 \pm 1{ }^{\circ} \mathrm{C}\right.$, photoperiod 16:8).

Knock down (KD) at $1 \mathrm{~h}$, mortality $(\mathrm{M})$ at $24 \mathrm{~h}$, and leg autotomy (LA) (self-amputation of one or more legs) at 1 and $24 \mathrm{~h}$ after exposure of males to an attracticide (treatment or blank) droplet or a vacuum handling control were recorded. Mortality was characterized by individuals on their backs and making no or very weak, movements of appendages. Knock down was characterized by males that remained on their backs but made strong erratic movements. Knock down (1 h), M (24 h), and LA (1 and 
$24 \mathrm{~h}$ ) were also recorded for female moths paired with conspecific males exposed to an attracticide treatment or blank or vacuum handling. In addition, female moth fertility (percentage of females laying egg masses during $96 \mathrm{~h}$ ) and fecundity (percentage of egg masses producing larvae and number of neonate larvae hatching per egg mass during $2 \mathrm{wk}$ ) were also recorded.

A total of 80 C. rosaceana (20 per replicate) and 60 P. pyrusana (15 per replicate) male moths were exposed to each aged attracticide treatment, attracticide blank, and vacuum handling (control) in a completely randomized design. Four replicates of each treatment were used and a one-way ANOVA and Tukey test $(\mathrm{p}=0.05)$ were conducted to compare responses between treatments. Percentage data were transformed using arcsine and square root prior to analysis, to comply with analysis assumptions. The number of larvae hatching from egg masses was transformed with a square root plus 0.5 prior to analysis. Chi-square was used to test for dependence between the proportion of legs autotomized and attracticide age categories for both species and sexes (Zar, 1996). F-values are shown in Tables 1, 2, and 3. All P-values were lower than 0.001 (SAS Institute, 2002), except some shown in Table 3. Chi-square values for Tables 4 and 5 are shown with results.

\section{RESULTS}

Temperatures during aging of the attracticide droplets were typical of summer conditions in eastern Washington. The average maximum and minimum temperatures were 30.4 and $13.4{ }^{\circ} \mathrm{C}$, wind speed was light averaging $1.2 \mathrm{~m}$ $\mathrm{s}^{-1}$, and there was no precipitation. Although humidity was not recorded it is typically very low during this period, ranging between $15-20 \%$ during the day.

Knock down (KD), mortality (M), and leg autotomy (LA) data for C. rosaceana and $P$. pyrusana male moths are shown in Table 1. All of the aged attracticide treatments had significantly greater KD, M and LA than the vacuum handled control and attracticide blank (permethrin-free), but the latter treatments were not different from each other in any assessment category. For both species, $\mathrm{M}$ or $\mathrm{KD}$ levels in the vacuum handled attracticide blank treatment were $3.3 \%$ or less, and LA values were $1.7 \%$ or less. On the other hand, KD for C. rosaceana and P. pyrusana was very high, $\geq 85 \%$ and $\geq 75 \%$, respectively, after a brief contact with any of the aged attracticide treatments. Knocked down P. pyrusana and C. rosaceana males were on their backs, made strong and erratic movements of the body and appendages, regurgitated liquid droplets from the proboscis, and extended their mouthparts. There was no difference in the KD levels for any of the aged attracticide treatments in P. pyrusana and only the 0-days attracticide

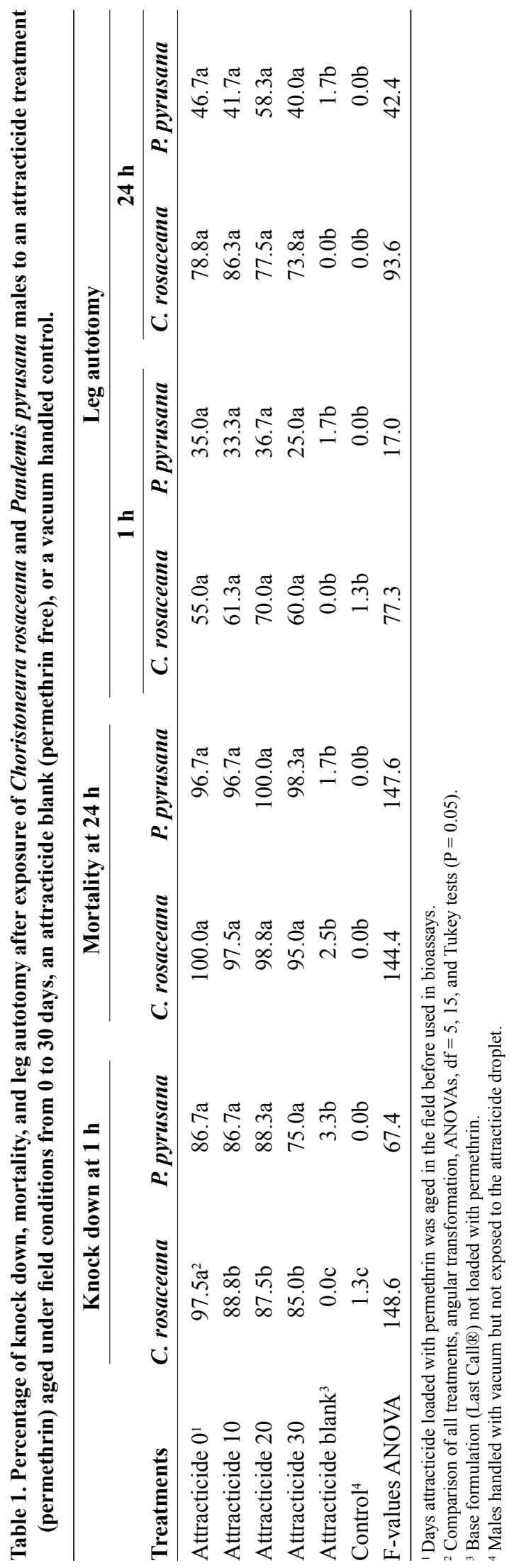


Table 2. Proportion of Choristoneura rosaceana $(\mathrm{n}=\mathbf{8 0}$ individuals per attracticide age category) or Pandemis pyrusana $(n=60)$ males dropping 0 to 6 legs $24 \mathrm{~h}$ after exposure to the attracticide treatment aged between 0 and 30 days under field conditions.

\begin{tabular}{llccccccc}
\hline \multirow{2}{*}{$\begin{array}{l}\text { Attracticide } \\
\text { aged (days) }\end{array}$} & \multicolumn{7}{c}{ Autotomized legs after exposure } \\
\cline { 3 - 9 } & \multicolumn{1}{c}{ Species } & $\mathbf{0}$ & $\mathbf{1}$ & $\mathbf{2}$ & $\mathbf{3}$ & $\mathbf{4}$ & $\mathbf{5}$ & $\mathbf{6}$ \\
\hline 0 & C. rosaceana & 0.21 & 0.34 & 0.25 & 0.14 & 0.05 & 0.01 & 0.00 \\
& P. pyrusana & 0.53 & 0.28 & 0.13 & 0.02 & 0.03 & 0.00 & 0.00 \\
10 & C. rosaceana & 0.14 & 0.29 & 0.35 & 0.13 & 0.08 & 0.03 & 0.00 \\
& P. pyrusana & 0.58 & 0.32 & 0.05 & 0.05 & 0.00 & 0.00 & 0.00 \\
20 & C. rosaceana & 0.23 & 0.21 & 0.25 & 0.24 & 0.06 & 0.00 & 0.01 \\
& P. pyrusana & 0.42 & 0.33 & 0.12 & 0.10 & 0.03 & 0.00 & 0.00 \\
30 & C. rosaceana & 0.26 & 0.24 & 0.29 & 0.16 & 0.05 & 0.00 & 0.00 \\
& P. pyrusana & 0.60 & 0.27 & 0.10 & 0.00 & 0.02 & 0.02 & 0.00 \\
\multirow{3}{*}{ Total } & C. rosaceana & 0.21 & 0.27 & 0.28 & 0.17 & 0.06 & 0.01 & 0.003 \\
& P. pyrusana & 0.53 & 0.30 & 0.10 & 0.04 & 0.02 & 0.004 & 0.00 \\
\hline
\end{tabular}

Table 3. Percentage of knock down, mortality, leg autotomy, female laying egg masses, viable egg masses, and number of larvae per viable egg mass, for Choristoneura rosaceana females paired with an intoxicated male previously exposed to an attracticide treatment aged in the field for different durations, attracticide blank, or vacuum handled control.

\begin{tabular}{|c|c|c|c|c|c|c|}
\hline \multirow[b]{2}{*}{ Treatments } & \multirow{2}{*}{$\begin{array}{c}\text { Knock down } \\
\text { at } 1 \mathrm{~h}\end{array}$} & \multicolumn{2}{|c|}{$24 h^{1}$} & \multirow{2}{*}{$\begin{array}{c}\text { Females laying } \\
\text { egg masses }\end{array}$} & \multirow{2}{*}{$\begin{array}{c}\text { Viable egg } \\
\text { masses }^{3}\end{array}$} & \multirow{2}{*}{$\begin{array}{c}\text { Average larva } \\
\text { number }^{4}\end{array}$} \\
\hline & & Mortality & Leg autotomy & & & \\
\hline Attracticide 0 & $3.8 b c^{5}$ & $55 \mathrm{a}$ & $26.3 \mathrm{a}$ & $13.8 \mathrm{~b}$ & $0.0 \mathrm{c}$ & $0 \mathrm{c}$ \\
\hline Attracticide 10 & $2.5 \mathrm{bc}$ & $40 \mathrm{a}$ & $23.8 \mathrm{a}$ & $21.3 b$ & $2.5 \mathrm{c}$ & $17 \mathrm{c}$ \\
\hline Attracticide 20 & $12.5 \mathrm{a}$ & $55 \mathrm{a}$ & $36.3 \mathrm{a}$ & $11.3 b$ & $0.0 \mathrm{c}$ & $0 \mathrm{c}$ \\
\hline Attracticide 30 & $6.3 \mathrm{ab}$ & $40 \mathrm{a}$ & $10.0 \mathrm{~b}$ & $17.5 b$ & $0.0 \mathrm{c}$ & $0 \mathrm{c}$ \\
\hline Attracticide blank & $0.0 \mathrm{c}$ & $0 \mathrm{~b}$ & $0.0 \mathrm{c}$ & $83.8 \mathrm{a}$ & $21.3 b$ & $58 \mathrm{~b}$ \\
\hline Control & $0.0 \mathrm{c}$ & $\mathrm{Ob}$ & $0.0 \mathrm{c}$ & $83.8 \mathrm{a}$ & $53.8 \mathrm{a}$ & $173 a$ \\
\hline F-values ANOVA & 11.0 & 39.1 & 52.1 & 27.6 & 53.7 & 22.8 \\
\hline
\end{tabular}

${ }^{1}$ No leg autotomy was observed at $1 \mathrm{~h}$ evaluation.

${ }^{2}$ Percentage of females laying egg masses (at $96 \mathrm{~h}$ after exposure).

${ }^{3}$ Percentage of females laying viable egg masses.

${ }^{4}$ Average number of first instar larvae per viable egg mass ( $2 \mathrm{wk}$ after the bioassay was conducted).

${ }^{5}$ Comparison of all treatments, angular transformation, ANOVAs, $\mathrm{df}=5,15$, and Tukey tests $(\mathrm{P}=0.05)$.

treatment was different from the other attracticide ages in C. rosaceana (Table 1). Mortality was greater than $96 \%$ with fresh attracticide (0-day) for both species, and was still above 95\% (C. rosaceana) and 98\% (P. pyrusana), in the 30-days attracticide treatment. No significant decrease in $\mathrm{M}$ was observed between the different ages of the attracticide treatment.

The percentage of LA at $1 \mathrm{~h}$ for $C$. rosaceana ranged $55-70 \%$, whereas it ranged for P. pyrusana $25-37 \%$ (Table 1). Leg autotomy increased by 10 to $20 \%$ in both species between the 1 and $24 \mathrm{~h}$ evaluation for a given attracticide treatment. Leg autotomy reached a maximum of $86.3 \%$ (dropping one or more legs per individual) in C. rosaceana males exposed to the 10-days old attracticide treatment.
This is the highest LA level reported so far (compared with Moore et al., 1992 (52\%) LA in males of Plutella xylostella [L.] [Plutellidae]) and Ortego and Bowers (1996) (60\% LA in nymphs of Shistocerca americana [Drury] [Orthoptera: Achrididae]), and yet above the $62.7 \%$ reported previously by Curkovic and Brunner (2005), although a slightly different aging procedure was employed in that study. Up to $58.3 \%$ males exposed to the 20-days old attracticide treatment were observed dropping at least one leg in P. pyrusana (also above the $40.5 \%$ previously reported).

There was no dependence between the number of legs autotomized and attracticide treatment age for males of either species $\left(C\right.$. rosaceana, $\chi^{2}$ calculated $=18.70$ vs. $\chi^{2}$ 
from table $[\alpha=0.05, \mathrm{df}=18]=28.87 ;$ P. pyrusana, $\chi^{2}$ calculated $=18.80$ vs. $\chi^{2}$ from table $[\alpha=0.05, \mathrm{df}=15]=$ 25.00 ). About $53 \%$ (42 to $60 \%$ ) of P. pyrusana males did not drop any legs after exposure to an aged attracticide treatment whereas only $21.3 \%(20-25 \%)$ of $C$. rosaceana males did not drop any legs. Of the P. pyrusana dropping legs most, $64 \%$, dropped one leg, $21 \%$ dropped two legs and none dropped all legs. Of the C. rosaceana dropping legs, 34\% dropped one, $36 \%$ dropped two, $21 \%$ dropped three and one dropped all six legs (Table 4).

No KD, M or LA were observed in females of either species paired to a male previously exposed to the attracticide blank or vacuum handled control treatments. A small percentage of C. rosaceana (2.5 to $12.5 \%$, Table 2) and of P. pyrusana (3.3-10\%, Table 3) female moths exhibited KD symptoms $1 \mathrm{~h}$ after exposure to an intoxicated male, but there was no relationship between the KD level and attracticide treatment age. Female moths had an average $\mathrm{M}$ between 40 and $55 \%$ in C. rosaceana and between 33 and $40 \%$ in P. pyrusana with no significant differences between attracticide treatment ages.

Most $C$. rosaceana females (83.8\%) paired with a nonintoxicated male (vacuum handled control or attracticide blank) laid at least one egg mass but few of these (21-54\%) produced larvae (Table 2). There were significantly fewer viable egg masses and hatched larvae in the attracticide blank treatment compared to the vacuum handled control. These results suggested that the pheromone in the attracticide blank, or some other unknown factor, had an effect, either on the $C$. rosaceana male's ability to mate or on C. rosaceana female fertility. The percentage of C. rosaceana females that laid egg masses after being exposed to intoxicated males was significantly lower than of those paired with non-intoxicated males and almost none of these egg masses produced viable larvae (Table 2).

Half $P$. pyrusana females (51.7\%) paired with a vacuum handled control male laid at least one egg mass and most of these egg masses $(>83 \%)$ produced larvae (Table 3). Fewer females (28.3\%) paired with a male from the attracticide blank treatment deposited egg masses but a high percentage of those eggs ( $>88 \%)$ hatched. The number of larvae per egg mass was not different from those of females exposed to the vacuum handled control male (Table 3). A low percentage (3-17\%) of P. pyrusana females exposed to intoxicated males produced egg masses but none produced viable eggs or larvae.

Leg autotomy (24-h) of female moths exposed to an intoxicated male ranged between $10-36 \%$ in C. rosaceana and $10-15 \%$ in P. pyrusana with little difference between attracticide treatment ages. As in males, there was no dependence of LA and attracticide treatment age $(C$. rosaceana, $\chi^{2}$ calculated $=17.24$ vs. $\chi^{2}$ from table $[\alpha=$ $0.05, \mathrm{df}=12]=21.03 ;$ P. pyrusana, $\chi^{2}$ calculated $=6.17$ vs. $\chi^{2}$ from table $[\alpha=0.05, \mathrm{df}=9]=16.92$, for both species) (Table 5). About $87 \%$ of $P$. pyrusana and $75 \%$ of $C$. rosaceana females dropped no legs. Between 8 and $14 \%$ of $P$. pyrusana and C. rosaceana, respectively, dropped only one leg, 3 to $8 \%$ dropped two legs, 1.7 to $2.5 \%$ dropped three, and $0.4-0.3 \%$ dropped four legs.

Table 4. Percentage of knock down, mortality, leg autotomy, female lying egg masses, viable egg masses, and number of larvae per viable egg mass, for Pandemis pyrusana females paired with an intoxicated male previously exposed to an attracticide treatment aged in the field for different durations, an attracticide blank, or vacuum handled control.

\begin{tabular}{|c|c|c|c|c|c|c|}
\hline \multirow[b]{2}{*}{ Treatments } & \multirow{2}{*}{$\begin{array}{l}\text { Knock down } \\
\text { at } 1 \mathrm{~h}\end{array}$} & \multicolumn{2}{|c|}{$24 h^{1}$} & \multirow{2}{*}{$\begin{array}{c}\text { Females laying } \\
y \\
\text { egg masses }^{2}\end{array}$} & \multirow{2}{*}{$\begin{array}{l}\text { Viable egg } \\
\text { masses }^{3}\end{array}$} & \multirow{2}{*}{$\begin{array}{c}\text { Average larvae } \\
\text { number }^{4}\end{array}$} \\
\hline & & Mortality & Leg autotomy & & & \\
\hline Vacuum & $0.0 \mathrm{~b}^{5}$ & $0.0 \mathrm{a}$ & $0.0 \mathrm{~b}$ & $51.7 \mathrm{a}$ & $83.9 \mathrm{a}$ & $15.3 \mathrm{a}$ \\
\hline Attracticide blank & $0.0 \mathrm{~b}$ & $0.0 \mathrm{a}$ & $0.0 \mathrm{~b}$ & $28.3 \mathrm{ab}$ & $88.4 \mathrm{a}$ & $21.3 \mathrm{a}$ \\
\hline Attracticide 0 & $3.3 \mathrm{ab}$ & $35.0 \mathrm{~b}$ & $10.0 \mathrm{ab}$ & $3.3 \mathrm{c}$ & $0.0 \mathrm{~b}$ & $0.0 \mathrm{~b}$ \\
\hline Attracticide 10 & $6.7 \mathrm{ab}$ & $40.0 \mathrm{~b}$ & $15.0 \mathrm{a}$ & $5.0 \mathrm{bc}$ & $0.0 \mathrm{~b}$ & $0.0 \mathrm{~b}$ \\
\hline Attracticide 20 & $10.0 \mathrm{a}$ & $33.3 b$ & $11.7 \mathrm{a}$ & $11.7 \mathrm{bc}$ & $0.0 \mathrm{~b}$ & $0.0 \mathrm{~b}$ \\
\hline Attracticide 30 & $3.3 \mathrm{ab}$ & $38.3 b$ & $13.3 \mathrm{a}$ & $16.7 \mathrm{bc}$ & $0.0 \mathrm{~b}$ & $0.0 \mathrm{~b}$ \\
\hline Control & $0.0 \mathrm{~b}$ & $0.0 \mathrm{a}$ & $0.0 \mathrm{~b}$ & $51.7 \mathrm{a}$ & $83.9 \mathrm{a}$ & $15.3 \mathrm{a}$ \\
\hline F-values ANOVA & 4.5 & 34.9 & 6.3 & 7.2 & 33.4 & 451.1 \\
\hline P-values ANOVA & 0.008 & $<0.001$ & 0.002 & $<0.001$ & $<0.001$ & $<0.001$ \\
\hline
\end{tabular}

\footnotetext{
${ }^{1}$ No leg autotomy was observed at $1 \mathrm{~h}$ evaluation.

${ }^{2}$ Percentage of females laying egg masses (at $96 \mathrm{~h}$ after exposure).

${ }^{3}$ Percentage of females laying viable egg masses.

${ }^{4}$ Average number of first instar larvae per viable egg mass $(\sim 2 \mathrm{wk}$ after the bioassay was conducted $)$.

${ }^{5}$ Comparison of all treatments, angular transformation, ANOVAs, $\mathrm{df}=5,15$, and Tukey tests $(\mathrm{P}=0.05)$.
} 
Table 5. Proportion of Choristoneura rosaceana $(\mathrm{n}=\mathbf{8 0}$ individuals per attracticide-aged category) or Pandemis pyrusana $(n=60)$ females dropping 0 to 4 legs $24 \mathrm{~h}$ after being paired with a male exposed to an attracticide treatment aged between 0 and 30 days under field conditions.

\begin{tabular}{llccccc}
\hline \multirow{2}{*}{$\begin{array}{l}\text { Attracticide } \\
\text { aged (days) }\end{array}$} & \multicolumn{5}{c}{ Autotomized legs after exposure } \\
\cline { 3 - 7 } 0 & \multicolumn{1}{c}{ Species } & $\mathbf{0}$ & $\mathbf{1}$ & $\mathbf{2}$ & $\mathbf{3}$ & $\mathbf{4}$ \\
\hline 0 & C. rosaceana & 0.74 & 0.15 & 0.09 & 0.03 & 0.00 \\
& P. pyrusana & 0.88 & 0.08 & 0.03 & 0.00 & 0.00 \\
10 & C. rosaceana & 0.73 & 0.16 & 0.08 & 0.03 & 0.01 \\
& P. pyrusana & 0.85 & 0.10 & 0.03 & 0.02 & 0.00 \\
20 & C. rosaceana & 0.64 & 0.2 & 0.125 & 0.04 & 0.00 \\
& P. pyrusana & 0.88 & 0.07 & 0.03 & 0.02 & 0.00 \\
30 & C. rosaceana & 0.89 & 0.05 & 0.05 & 0.01 & 0.00 \\
& P. pyrusana & 0.85 & 0.12 & 0.00 & 0.03 & 0.00 \\
Total & C. rosaceana & 0.75 & 0.14 & 0.08 & 0.03 & 0.003 \\
& P. pyrusana & 0.87 & 0.08 & 0.03 & 0.02 & 0.004 \\
\hline
\end{tabular}

\section{DISCUSSION}

Curkovic and Brunner (2005) reported a significant linear decline in male mortality and attracticide treatment age. Similar information has been reported by Charmillot $e t$ al. (2000) on C. pomonella and Suckling and Brockerhoff (1999) on E. postvittana. The main difference between this study and that of Curkovic and Brunner (2005) was the method of aging the attracticide. When the attracticide treatment was aged on foil the shape of the droplet was well maintained, as compared the droplet placed on apple tree bark (Curkovic and Brunner, 2005) where the droplet spread and dried or dissipated over time. The particular mechanism explaining this result is unknown, but it is possible that either the attracticide droplets applied to bark change the nature of their formulation enough to expose the permethrin to a quicker degradation or that the toxicant is absorbed into the bark making it less available to the moth. In fact, Poullot et al. (2001) found differences in the toxic effect from an attracticide on $C$. pomonella depending on the substrate surface. In addition, several reports demonstrate that bark has a high affinity with hydrophobic compounds and has been reported as a substrate capable of pesticides sorption (Brás et al., 1999). Specifically, permethrin treated almond (Prunus amygdalus Batsch) twigs were found to contain measurable bark surface permethrin residues several months after application (Zalom et al., 2001). The results from this study strongly indicate it would be an advantage to provide this attracticide formulation on an impervious surface in order to maintain its toxicity.

Knock down symptoms of $P$. pyrusana and $C$. rosaceana intoxicated males were similar to those observed in different insect species exposed to pyrethroids (Nuessly and Matthen, 2004; Curkovic and Brunner, 2005). These symptoms would likely limit P. pyrusana and C. rosaceana males ability to find and mate with females, as indicated by De Souza et al. (1992) who obtained similar results with Spodoptera littoralis (Boisduval) (Lepidoptera: Noctuidae) males after exposure to an attracticide.

Leg autotomy has been described for several other Lepidoptera species, including C. pomonella, Sitotroga cerealella (Olivier) (Gelechidae), and P. xylostella (Moore et al., 1989; Moore and Tabashnik, 1989; Krupke, 1999; Curkovic and Brunner, 2005). The level of leg autotomy found in adult males was the highest reported so far compared to Moore et al., 1992 (52\% leg autotomy in males of P. xylostella [L.] [Plutellidae]), Ortego and Bowers (1996) (60\% leg autotomy in nymphs of $S$. americana [Drury] [Orthoptera: Achrididae]), yet above the $62.7 \%$ reported previously by Curkovic and Brunner (2005), although a slightly different aging procedure was employed in that study. The physiological response in $S$. americana nymphs autotomizing their legs has been studied by Ortego and Bowers (1996), and their ecological effects on arthropods has also been discussed previously by Randall (1981), Eisner and Camazine (1983), Carlberg (1986), and Curkovic and Brunner (2005). Our results suggest leg autotomy is not in response to handling, physical damage or exposure to a non-toxic sticky substrate, but to the presence of the toxicant, permethrin, in the attracticide. The autotomy observed can arise from the mode of action of various chemicals causing leg autotomy in insects. Moore and Tabashnik (1989) reported leg autotomy in diamondback moth (Plutella xyllostella (L.) adults after exposure to 
fenvalerate. There are also reports of leg autotomy in Lepidoptera and other insects when exposed to permethrin and DDT (dichlorodiphenyltrichloroethane), that target sodium channels in peripheral nerves (Wolansky et al., 2006). Likewise, Ortego and Bowers (1996) reported that pyrethroids at $0.5 \mu \mathrm{gg}^{-1}$ body weight of $S$. americana caused $50 \%$ leg autotomy in $1 \mathrm{~h}$; while most other insecticides classes (e.g., organophosphates) required much higher doses, $200 \mu \mathrm{g} \mathrm{g}^{-1}$, to achieve the same response. These observations would point to the peripheral nerves in the leg that trigger leg autotomy. Once these nerves are damaged by the crushing action of a predator's attack, or disrupted by chemicals keeping the sodium channel open, leg autotomy will result. However, the mechanism controlling this response remains unknown.

Previous reports did not record specific information on female mortality after some type of exposure to insecticide-loaded attracticides. In this case, females became intoxicated by contact with the male and/or by the deposit of attracticide on the internal surface of the cup coming from the intoxicated male moth. It is possible that a sub-lethally intoxicated male would be able, in the confined arena (cup) to find a female for courtship and mating since they become highly excited after exposure to pheromone-loaded attracticides (Curkovic and Brunner 2006; Curkovic et al., 2006), and this contact, although unlikely to copulate under the intoxicated condition, resulted in a negative impact, especially because that no repellency has been observed when moths are exposed to permethrin-loaded attracticides (Curkovic and Brunner, 2006). In nature, therefore, if an intoxicated male would be capable of locating a mate, the female could be affected by the contact and probably become unable to lay viable eggs.

\section{CONCLUSIONS}

Attracticide formulations can be useful for pest management if there is contact between the target species and the source (attracticide droplet), allowing insects to acquire enough toxicant to either kill or severely damage them. Previous data (Curkovic et al., in press) suggest that both $C$. rosaceana and $P$. pyrusana males contact attracticide droplets in a similar way as they perform courtship to females (Curkovic et al., 2006). We developed a bioassay to standardize contact exposure and test the attracticide efficacy to kill males of both species. A very brief contact between male moths of the two species and the attracticide formulation actually caused both lethal (above 95\%), or severe sub lethal effects (as leg autotomy that should render males unable to walk). Besides, the attracticide was highly active in killing moths of both species, even after 30 days under field conditions, indicating that droplets have a long residual insecticidal activity if not absorbed in the bark. We also investigated the possibility of female intoxication by attracticide exposure after being paired with a previously intoxicated male. Our results demonstrate that a significant proportion of females can be either killed (above 33\%) or disabled to mate and/or reproduce when paired with intoxicated males, although the exact mechanism reducing fertility remains unclear. These findings suggest that if a male can survive from the original contact with the attracticide droplet and somehow reach a female, it might kill her or reduce reproduction. Overall, these data suggest a high potential for attracticides to control leafroller pests, but it is still necessary to evaluate their attraction over time as well as their performance under field conditions and at the population level.

\section{ACKNOWLEDGEMENTS}

We acknowledge the technical assistance from Phillip Kirsch and Darek Czokajlo (IPM Technologies, Portland, Oregon, USA) in providing the base attracticide matrix; the assistance of Kathy Pierre in maintaining leafroller colonies and the statistical advice of Dr. Richard Alldredge, Department of Statistics Washington State University. In addition, we acknowledge the financial support provided by the Washington Tree Fruit Research Commission and from the Washington Commission on Pesticide Registration.

\section{RESUMEN}

Toxicidad de atracticidas en base a permetrina envejecidos en campo, sobre machos y hembras adultas de Choristoneura rosaceana (Harris) and Pandemis pyrusana Kearfott (Lepidoptera: Tortricidae). Los efectos letales y subletales sobre machos de Choristoneura rosaceana (Harris) and Pandemis pyrusana Kearfott expuestos a un atracticida basado en permetrina, envejecido en condiciones de campo, fueron evaluados en laboratorio. También se evaluó el efecto de emparejar hembras conespecíficas con machos previamente intoxicados. En ambas especies se observó mortalidad de machos significativamente mayor ( $\geq 95 \%$ ) 24 h post exposición al atracticida. Asimismo, altos niveles de "volteo" de individuos $(\geq 75 \%)$ se observaron en machos de ambas especies $1 \mathrm{~h}$ post exposición al atracticida. En hembras, el nivel de "volteo" fue $\geq 2,5 \%$ y la mortalidad $\geq 3,3 \%$ luego del emparejamiento con machos intoxicados. Veinticuatro h post exposición el nivel de auto amputación de patas en machos expuestos al atracticida fue al menos $73 \%$ en $C$. rosaceana y $\geq 41 \%$ en $P$. pyrusana, mientras 
que fue $\geq 10 \%$ entre hembras de ambas especies luego del emparejamiento con machos intoxicados. Las polillas expuestas a un atracticida "blanco" (sin permetrina) mostraron niveles significativamente menores en todos los parámetros evaluados $(0-3,3 \%)$. La fecundidad y fertilidad también fueron significativamente afectadas por el emparejamiento con machos intoxicados. No se observó una reducción significativa en la mortalidad, auto-amputación de patas ni en la fecundidad asociada al tiempo que fue envejecido el atracticida. Los resultados sugieren un alto potencial para el uso de atracticidas contra estas dos especies de tortrícidos.

Palabras clave: bioensayos, fecundidad, fertilidad, "volteo", auto-amputación de patas, efectos letales, mortalidad, efectos subletales.

\section{LITERATURE CITED}

Beers, E.H., J.F. Brunner, M.J. Willett, and G.M. Warner. 1993. Orchard pest management: A resource book for the Pacific Northwest. 276 p. Good Fruit Grower, Yakima, Washington, USA.

Brás, I.P., L. Santos, and A. Alves. 1999. Organochlorine pesticides removal by pinus bark sorption. Environ. Sci. Technol. 33:631-634.

Brunner, J.F. 1999. New pests: a challenge for area wide programs. Proc. Wash. State Hortic. Assoc. 95:154158.

Carlberg, U. 1986. Thanatosis and autotomy as defense in Baculum sp.1 (Insecta: Phasmida). Zool. Anz. 217:3953.

Charmillot, P.J., D. Hofer, and D. Pasquier. 2000. Attract and kill: a new method for control of the codling moth Cydia pomonella. Entomol. Exp. Appl. 94:211-216.

Curkovic, T. 2004. Behavioral responses of Choristoneura rosaceana (Harris) and Pandemis pyrusana Kearfott males to attracticide sources. 175 p. Ph.D. dissertation. Washington State University, Pullman, Washington, USA.

Curkovic, T., and J.F. Brunner. 2003. Assessment of an attracticide formulation to control Cydia pomonella (L.) (Lepidoptera: Tortricidae) in apple orchards in Washington State, USA. Agric. Tec. (Chile) 63:231239.

Curkovic, T., and J.F. Brunner. 2005. Residual and sub-lethal effects of an attracticide formulation on Choristoneura rosaceana (Harris), Pandemis pyrusana Kearfott, and Cydia pomonella (L.) males (Lepidoptera: Tortricidae). Crop Prot. 24:637-641.
Curkovic, T., and J.F. Brunner. 2006. Evaluation of permetrhin for attracticide development against Choristoneura rosaceana and Pandemis pyrusana (Lepidoptera: Tortricidae) males. Crop Prot. 25:973976.

Curkovic, T., and J.F. Brunner. 2007. Choristoneura rosaceana (Harris) and Pandemis pyrusana Kearfott (Lepidoptera: Tortricidae) male control in Washington State (USA) apple orchards treated with different source densities of several attracticide formulations. Agric. Tec. (Chile) 67:23-28.

Curkovic, T., J.F. Brunner, and P. Landolt. 2006. Courtship behavior of Choristoneura rosaceana (Harris) and Pandemis pyrusana Kearfott (Lepidoptera: Tortricidae). Ann. Entomol. Soc. Am. 99:617-624.

Curkovic, T., J.F. Brunner, and P. Landolt. Field and laboratory responses of male Choristoneura rosaceana and Pandemis pyrusana to pheromone concentrations in an attracticide paste formulation. J. Insect Sci. (in Press).

De Souza, K.R., L.J. McVeigh, and D.J. Wright. 1992. Selection of insecticides for lure and kill studies against Spodoptera littoralis (Lepidoptera: Noctuidae). J. Econ. Entomol. 85:2100-2106.

Delisle, J. 1995. Effect of male and female age on the mating success of the obliquebanded leafroller, Choristoneura rosaceana (Lepidoptera: Tortricidae) under different ecological conditions. J. Insect Behav. 8:781-799.

Dunley, J.E., J.F. Brunner, M.D. Doerr, and E.H. Beers. 2006. Resistance and cross-resistance in populations of Choristoneura rosaceana and Pandemis pyrusana (Lepidoptera: Tortricidae) in Washington apple. J. Insect Sci. 6. Article 14. 7 p. Available at http://www. insectscience.org/6.14 (Accessed 25 August 2006).

Eisner, T., and S. Camazine. 1983. Spider leg autotomy induced by prey venom injection: An adaptative response to "pain"? Proc. Natl. Acad. Sci. USA 80:3382-3385.

Evenden, M., and J.R. McLaughlin. 2005. Male Oriental fruit moth response to a combined pheromone-based attracticide formulation targeting both Oriental fruit moth and codling moth (Lepidoptera: Tortricidae). J. Econ. Entomol. 98:317-325.

Haynes, K.F., W.G. Li, and T.C. Baker. 1986. Control of pink bollworm (Lepidoptera: Gelechiidae) with insecticides and pheromones (Attracticide): Lethal and sub lethal effects. J. Econ. Entomol. 79:1466-1471.

Krupke, C.H. 1999. Behavioral response of male codling moth (Cydia pomonella (L.)) to a semiochemicalbased attract and kill management strategy. 81 p. M.S. thesis. Simon Fraser University, Vancouver, British Columbia, Canada. 
Krupke, C.H., B.D. Roitberg, and G.J.R. Judd. 2002. Field and laboratory responses of male codling moth (Lepidoptera: Tortricidae) to a pheromone-based attract-and-kill strategy. Environ. Entomol. 31:189197.

Moore, A., and B.E. Tabashnik. 1989. Leg autotomy of adult diamondback moth (Lepidoptera: Plutellidae) in response to tarsal contact with insecticide residues. J. Econ. Entomol. 82:1624-1627.

Moore, A., B.E. Tabashnik, and M.D. Rethwisch. 1992. Sub lethal effects of fenvalerate on adults of the diamondback moth (Lepidoptera: Plutellidae). J. Econ. Entomol. 85:381-384.

Moore, A., B.E. Tabashnik, and J.D. Stark. 1989. Leg autotomy: a novel mechanism of protection against insecticide poisoning in diamondback moth (Lepidoptera: Plutellidae). J. Econ. Entomol. 82:12951298.

Nansen, C., and T.W. Phillips. 2004. Attractancy and toxicity of an attracticide for indianmeal moth, Plodia interpunctella (Lepidoptera: Pyralidae). J. Econ. Entomol. 97:703-710.

Nuessly, G.S., and G. Matthen. 2004. Contact and leaf residue activity of insecticides against the sweet corn pest Euxesta stigmatias (Diptera: Otitidae). J. Econ. Entomol. 97:496-502.

Ortego, F., and W.S. Bowers. 1996. Induction of autotomy in the American bird grasshopper Schistocerca americana (Drury) by the ecdysone agonist RH-5849 and investigation of its mode of action. Experientia 52:42-50.

Phelan, P.L., and T.C. Baker. 1987. An attracticide for control of Amyelois transitiella (Lepidoptera: Pyralidae) in almonds. J. Econ. Entomol. 80:779783.

Poullot, D., D. Beslay, J.C. Bouvier, and B. Sauphanor. 2001. Is attract-and-kill technology potent against insecticide-resistant Lepidoptera? Pest Manage. Sci. 57:729-736.
Randall, J.B. 1981. Regeneration and autotomy exhibited by the black widow spider, Lactrodectus walckenaer, I. The legs. Rouxs Arch. Dev. Biol. 190:230-232.

Roelofs, W.L., R.F. Lagier, and S.C. Hoyt. 1977. Sex pheromone of the moth, Pandemis pyrusana. Environ. Entomol. 6:353-4.

SAS Institute. 2002. JMP statistics and graphics guide. $5^{\text {th }}$ ed. 225 p. SAS Institute, Cary, North Carolina, USA.

Schumacher, P., A. Weyeneth, D.C. Weber, and S. Dorn. 1997. Long flights in Cydia pomonella L. (Lepidoptera: Tortricidae) measured by a flight mill: influence of sex, mated status and age. Physiol. Entomol. 22:149-160.

Shorey, H.H., and R.L. Hale. 1965. Mass-rearing of the larvae of nine noctuid species on a simple artificial medium. J. Econ. Entomol. 58:522-524.

Suckling, D.M., and E.G. Brockerhoff. 1999. Control of light brown apple moth (Lepidoptera: Tortricidae) using an attracticide. J. Econ. Entomol. 92:367-372.

Tabashnik, B.E., M.D. Rethwisch, and M.W. Johnson. 1988. Variation in adult mortality and knockdown caused by insecticides among populations of diamondback moth (Lepidoptera: Plutellidae). J. Econ. Entomol. 81:437-441.

Vakenti, J.M., A.P. Gaunce, K.N. Slessor, G.G.S. King, S.A. Allan, H.F. Madsen, and J.H. Borden. 1988. Sex pheromone components of the obliquebanded leafroller, Choristoneura rosaceana, in the Okanagan valley of British Columbia. J. Chem. Ecol. 14:60521.

Wolansky, M.J., C. Gennings, and K.M. Crofton. 2006. Relative potencies for acute effects of pyrethroids on motor function in rats Toxicol. Sci. 89:271-277.

Zalom, F.G., M.W. Stimmann, T.S. Arndt, D.B. Walsh, C. Pickel, and W.H. Krueger. 2001. Analysis of permethrin (cis- and trans-isomers) and esfenvalerate on almond twigs and effects of residues on the predator mite Galendromus occidentalis (Acari: Phytoseiidae). Environ. Entomol. 30:70-75.

Zar, J. 1996. Biostatistical analysis. $3^{\text {rd }}$ ed. 662 p. PrenticeHall International, Englewood Cliffs, New Jersey, USA. 